\section{(6) OPEN ACCESS}

\title{
Choose to test: self-selected testing for sexually transmitted infections within an online service
}

\author{
Jonathan Syred, ${ }^{\circledR}$ Gillian Holdsworth, Chris Howroyd, Kez Spelman, Paula Baraitser
}

- Additional material is published online only. To view please visit the journal online (http://dx.doi.org/10.1136/ sextrans-2018-053796).

School of Population Health and Environmental Sciences, King's College London, London, UK

\section{Correspondence to} Dr Paula Baraitser, Adult Nursing, Weston Education Centre, Kings College London, London SE5 9RJ, UK; paula. baraitser@kcl.ac.uk

Received 5 September 2018 Revised 22 January 2019 Accepted 26 January 2019 Published Online First 5 March 2019

\section{Check for updates}

\section{(C) Author(s) (or their} employer(s)) 2019. Re-use permitted under CC BY-NC. No commercial re-use. See rights and permissions. Published by BMJ.

\section{To cite: Syred J,}

Holdsworth G, Howroyd C, et al. Sex Transm Infect

2019;95:171-174.

\begin{abstract}
Objective To describe the outcomes of user-led, choice of test within an online sexual health service.

Methods We analysed routinely collected data from a free, online sexual health service in Essex, UK that enabled users to select their tests. The service website provided information on all sexually transmitted infections, recommended a testing package based on sexuality and ethnicity, and invited users to modify this if they chose. Data on orders were analysed for the 6 months before (May-October 2016) and after (October-April 2017) implementation.
\end{abstract}

Results We compared 7550 orders from 6253 users before and 9785 orders from 7772 users after implementation. There was no difference in the proportion of chlamydia $(p=0.57)$ or gonorrhoea $(p=0.79)$ tests that were positive between the two periods. HIV and syphilis positives were too few in our sample during both periods for analysis. During implementation, men who have sex with men (530 users) were offered genital, rectal and oral chlamydia and gonorrhoea testing plus HIV and syphilis testing. In $17.2 \%$ of orders, users removed tests. Black or ethnic minority users excluding those who reported as men who have sex with men (805 users) were offered chlamydia, gonorrhoea and HIV testing. In $77.9 \%$ of orders, users added a test. All other users were offered chlamydia and gonorrhoea tests only. In $65.2 \%$ of orders, users added tests. We observed a reduction in orders of 3083 blood tests (31\%).

Conclusion Users engaged with the 'choose to test' intervention. Although a majority added tests, the intervention was cost saving by reducing the HIV and syphilis tests ordered.

\section{INTRODUCTION}

The fundamental roles of people in understanding and shaping their own healthcare are central to health outcomes. ${ }^{1}$ Shared decision-making, as part of user-centred care, is referenced in the National Health Service (NHS) Constitution ${ }^{2}$ and the Health and Social Care $\mathrm{Act}^{3}$. Health service users report wanting more involvement in clinical decisions. ${ }^{1}$

E-health care offers new opportunities for self-management outside clinical contexts, and with better access to information, it could expand shared decision-making in healthcare. ${ }^{4}$

Testing for STIs is increasingly accessible online. ${ }^{5}$ These services enable online ordering of sexual health tests that are delivered by post to users who collect their own samples and send these direct to a laboratory for analysis with results delivered by text message. The BASHH guidelines on testing for STIs recommend that asymptomatic sexual health service users should be tested for HIV, syphilis, chlamydia and gonorrhoea with the sites tested selected according to sexual behaviour. ${ }^{6}$ It also recommends testing for hepatitis B and C for some asymptomatic populations. ${ }^{6}$ Populations testing online have lower rates of STIs than those in walk-in sexual health clinics $^{7}$ and a more individually tailored and user selected package of testing may be appropriate in this context with information to support choice. This reflects a reality that online services may not exactly replicate the service model provided in clinic-based services and the importance of evaluation in understanding the impact of these differences.

We developed and piloted a service, 'choose to test', to support user-led, informed decision-making on choice of test within a free, UK NHS-commissioned, online, STI testing service (www.sh24. org.uk). The service was developed using UK Government Digital Design Principles (ww.gov. uk/design-principles) that involve collaborative service development with service users followed by the early release of simple versions of the service, testing it with users, deleting what does not work, making refinements based on feedback and slowly adding additional layers of functionality with continual optimisation. The version evaluated here was developed and piloted in Essex in the East of England, an area providing 17000 online tests per year.

The 'choose to test' service provided information on all STIs and advice that regular testing, particularly after a change of partner, is important. It provided personalised clinical support for those who test frequently. The service used an algorithm based on public health data comparing risk of STIs in different populations in the area of intervention to recommend the testing package. It invited users to modify this selection if they chose. Those accessing the online STI testing service are asked for information on their age, gender, ethnicity and sexuality. Based on information about the risk of each STI among different populations in Essex, their test choice page has the recommended tests preselected according to the criteria in table 1 , with information about the type of sample required for the test, a summary of how it is transmitted and a link to detailed information about each infection (online supplementary figures 1 and 2). Users are invited to select or deselect tests according to their preference. The service is not currently commissioned to 
Table 1 Algorithm for offering different packages of tests for the three population groups: non-men who have sex with men (MSM)/ non-black and ethnic minority (BME); BME; MSM

\begin{tabular}{llll}
\hline & Non-MSM/non-BME & BME & MSM \\
\hline Genital chlamydia/gonorrhoea & Yes & Yes & Yes \\
Oral chlamydia/gonorrhoea & No & No & Yes \\
Rectal chlamydia/gonorrhoea & No & No & Yes \\
Syphilis & No & No & Yes \\
HIV & No & Yes & Yes \\
\hline
\end{tabular}

provide hepatitis $\mathrm{B}$ and $\mathrm{C}$ testing online, but there is information on these infections, populations at risk and options for testing in clinics on the service website (www.sh24.org.uk/sexual-health).

The aim of this observational study was to describe user choice following the implementation of the 'choose to test' intervention and to investigate its effect on STI test orders and diagnoses. This will inform providers, researchers, commissioners and policy-makers about the impacts of introducing choice of tests to online-provided STI testing.

\section{METHODS}

Routinely collected data on all orders from the online sexual health services from people resident in the postcodes where the 'choose to test' service was provided were collated into a single database for the period 6 months before the introduction of 'choose to test' (1 May 2016 to 29 October 2016) and 6 months after its implementation (30 October 2016 to 30 April 2017). All order records were anonymised and harmonised into a single database. Each record included information on user demographics (age, gender, sexual orientation, postcode of residence, ethnicity), date of test, testing package offered, testing package chosen and test results. The unit of analysis was 'orders' although multiple orders from the same user could be linked in the database to identify different behaviour from the same user over time. The number of people accessing additional information by expanding the information icon was measured using website behavioural analytics software (www.kissmetrics.co.uk).

\section{Analysis}

User response to the 'choose to test' service was studied by measuring (1) the modification of the testing package recommended, (2) the number of views of the information provided, (3) the total cost of tests provided and (4) the number of infections diagnosed.

We described users of the service before and after the introduction of 'choose to test' using simple descriptive statistics. Subsequent analysis was based on orders rather than users as the factors affecting choice of test may vary between testing episodes.

We described modification of the service offer. We tested for associations between modification of the selected package and age, sex, ethnicity, sexual health risk and previous sexual health clinic use using the $\chi^{2}$ test. Variables that were significantly associated with test choice in univariate analysis were added to a multivariate model using logistic regression. We tested for associations between modification of the selected package among first order and subsequent order in the 'choose to test' period.

To calculate the reduction in numbers of test orders, we subtracted the actual numbers of tests ordered from the number that would have been ordered if everyone had been offered and completed all tests.
Table 2 Differences in users' demographics for pre-choice of test period vs choice of test period

\begin{tabular}{|c|c|c|c|c|c|}
\hline & \multicolumn{2}{|c|}{$\begin{array}{l}\text { Pre-choice of test } \\
\text { period }\end{array}$} & \multicolumn{2}{|c|}{ Choice of test period } & \multirow[b]{2}{*}{$P$ value } \\
\hline & $\mathrm{n}$ & $\%$ & $\mathbf{n}$ & $\%$ & \\
\hline All & 6253 & & 7772 & & \\
\hline Female & 4030 & $64.4 \%$ & 4968 & $63.9 \%$ & 0.52 \\
\hline $16-24$ & 3351 & $53.6 \%$ & 4120 & $53 \%$ & 0.49 \\
\hline BME & 642 & $10.3 \%$ & 878 & $11.3 \%$ & 0.05 \\
\hline MSM & 367 & $5.9 \%$ & 530 & $6.8 \%$ & 0.02 \\
\hline \multicolumn{6}{|l|}{ IMD } \\
\hline Most deprived & 580 & $9.3 \%$ & 794 & $10.2 \%$ & 0.02 \\
\hline 2 & 1364 & $21.8 \%$ & 1705 & $22 \%$ & \\
\hline 3 & 1399 & $22.4 \%$ & 1847 & $23.8 \%$ & \\
\hline 4 & 1614 & $25.8 \%$ & 1886 & $24.3 \%$ & \\
\hline Least deprived & 1296 & 20.7 & 1528 & $19.7 \%$ & \\
\hline
\end{tabular}

Bold values indicate statistical significance.

BME, black and ethnic minority; IMD, index of multi-deprivation; MSM, men who have sex with men.

We used behavioural analytics software (www.kissmetrics. com) to identify whether users had opened the information pages. We did not have these data for the same period as the testing data but used data from a subsequent 6-month period (1 June 2017 to 31 December 2017.

\section{RESULTS}

We analysed data from 7550 orders from 6253 users who ordered STI tests during the 6-month period before the introduction of 'choose to test' (1 May 2016 to 29 October 2016) and data from 9785 orders from 7772 users who ordered STI tests during the 6-month period after the introduction of 'choose to test' (30 October 2016 to 30 April 2017).

The age, sex, ethnicity and sexuality of users is described in table 2 and shows that the 6253 users of the service before the introduction of 'choose to test' were very similar to the 7772 users after implementation of the new service in terms of their age $(p=0.49)$, sex $(p=0.52)$ and ethnicity $(p=0.05)$. There was, however, a small increase in the number of MSM users in the 'choose to test' period $(p=0.02)$ and small shift towards a higher proportion of users from deprived areas ordering $(p=0.02)$.

All subsequent analysis is based on orders rather than users as the factors affecting choice of test may vary between testing episodes. Ninety-three per cent of all orders were from users who were asymptomatic at the time of ordering, and $27.2 \%$ of orders were from those who reported condomless sex in the 3 days prior to testing.

Users who self-identified as men who have sex with men (MSM) $(n=530)$ were offered genital, rectal and oral chlamydia and gonorrhoea tests in addition to HIV and syphilis tests. In $17.2 \%$ of orders from this group, the user chose to remove tests from this package. Users who self-identified as black or ethnic minority (BME), excluding those who also identified as MSM, were offered tests $(n=805)$ for chlamydia, gonorrhoea and HIV, and in $67.3 \%$ of orders from this group, the user chose to add a test for syphilis. Users in neither of these groups (non-BME/ non-MSM) $(n=6433)$ were offered chlamydia and gonorrhoea tests only and in $59.8 \%$ of orders from this group the user chose to add HIV and syphilis tests.

There were 5804 returned and viable tests from single orders for chlamydia and gonorrhoea in the pre-'choose to test' period 
Table 3 Differences in orders by demographics and positivity before and after the introduction of 'choose to test'

\begin{tabular}{|c|c|c|c|c|c|}
\hline & \multicolumn{2}{|c|}{ Pre-'choose to test' } & \multicolumn{2}{|c|}{$\begin{array}{l}\text { 'Choose to test' } \\
\text { period }\end{array}$} & \multirow[b]{2}{*}{$P$ value } \\
\hline & $\mathrm{n}$ & $\%$ & $\mathrm{n}$ & $\%$ & \\
\hline All & 7550 & & 9785 & & \\
\hline Female & 4954 & $65.60 \%$ & 6386 & $65.30 \%$ & 0.63 \\
\hline $16-24$ & 4127 & $54.70 \%$ & 5316 & $54.30 \%$ & 0.34 \\
\hline BME & 783 & $10.40 \%$ & 1094 & $11.20 \%$ & 0.08 \\
\hline MSM & 463 & $6.10 \%$ & 692 & $7.10 \%$ & 0.008 \\
\hline Chlamydia positives* & 358 & $6.20 \%$ & 433 & $5.90 \%$ & 0.57 \\
\hline Gonorrhoea positivity* & 29 & $0.50 \%$ & 39 & $0.50 \%$ & 0.79 \\
\hline HIV positives $\dagger$ & $<5$ & - & $<5$ & - & \\
\hline Syphilis positives† & $<5$ & - & $<5$ & - & - \\
\hline
\end{tabular}

*Chlamydia and gonorrhoea positivity calculated to include returned and viable samples only.

†Numbers under 5 are masked to prevent deductive identification.

BME, black and ethnic minority; MSM, men who have sex with men.

and 7297 in the period after implementation. The number of chlamydia diagnoses $(6.2 \%$ vs $5.9 \%, p=0.57)$ or gonorrhoea diagnoses $(0.5 \%$ vs $0.5 \%, \mathrm{p}=0.79)$ did not change significantly between the two periods (table 3 ). There were less than five HIV and syphilis diagnoses among groups that would have had this test as the default and among those that had modified their test package to receive this test.

Orders where the testing package was modified were from different groups than those where the default offer was chosen (table 4, online supplementary figure 3 ). Orders from women (adjusted OR [AOR] 1.24; 95\% CI 1.12 to 1.38 ) and BME groups (AOR 4.65; 95\% CI 3.84 to 5.64) were more likely to be modified. Orders from those aged 16 to 24 (AOR $0.72 ; 95 \%$ CI 0.66 to 0.79 ) MSM users (AOR $0.07 ; 95 \%$ CI 0.05 to 0.08 ) and users with symptoms (AOR 0.53 ; 95\% CI 0.46 to 0.63 ) were less likely to be modified. At univariate analysis, there was no significant difference in modification of the test package offered between orders from users who reported condomless sex in the last 3 days and those who reported never using a clinic before.
We observed a total reduction in orders of 3083 blood test kits for HIV and syphilis (31\%) between the two study periods with a $35 \%$ reduction in blood tests ordered by non-BME/non-MSM users and a $22 \%$ reduction in those for BME/non-MSM groups. There was very little difference in orders of tests for chlamydia and gonorrhoea $(<2 \%)$ in the non-BME/non-MSM groups. We did observe a reduction in orders for chlamydia and gonorrhoea among MSM users as some chose not to test from some sites and some chose to test for HIV or syphilis only. Orders for rectal sample kits reduced by over $10 \%$ and blood tests orders were reduced by just under 6\% among this group (online supplementary table 1).

To understand whether users made test choices on the basis of the information provided, we obtained data on the number of users accessing this information using web data analytics. We analysed instead a 6-month period from 1 June 2017 to 31 December 2017. During this period, just over 19000 users visited the selection page, 15512 users ordered a test and information on the test kits were accessed a total of 3873 times or by $20 \%$ of users.

\section{DISCUSSION}

Increasing acknowledgement of the importance of self-care ${ }^{8}$ is reflected in new ideas about shared decision-making which are now embedded in NHS policy. ${ }^{2}$ Shared decision-making overtly values the knowledge that people have about their health and health behaviours. Within consultations on sexual health testing, people bring personal preferences about when to test and what to test for, as well as important knowledge about their sexual networks and behaviours. Clinicians bring technical knowledge about the tests (eg, window periods) and public health knowledge about strategies to control STIs at a population level. An ideal decision-making process would reference all of these factors.

As decisions about sexual health testing are increasingly made within online services, ${ }^{5}$ new strategies to support them are required. 'Choose to test' is a first iteration of a service that aims to support informed choice in this context. We found orders increased over time, possibly reflecting increased local knowledge of the online service, a finding that is consistent with research in other areas. ${ }^{7}$ We also found that users tended to

Table 4 Characteristics of those who chose to modify their test package and those who did not

\begin{tabular}{|c|c|c|c|c|c|c|}
\hline & & Choose default test package & Modify test package & & & \\
\hline & $\mathrm{N}$ & $\mathrm{n}(\%)$ & $\mathrm{n}(\%)$ & $P$ value & OR $(95 \% \mathrm{Cl})$ & $\mathrm{AOR}(95 \% \mathrm{Cl})^{*}$ \\
\hline All & 9785 & 3472 & 6313 & & & \\
\hline Female & 6386 & $2141(61.7 \%)$ & $4245(67.2 \%)$ & $<0.001$ & 1.28 (1.17 to 1.39$)$ & 1.24 (1.12 to 1.38$)$ \\
\hline $16-24$ & 5316 & $2041(58.8 \%)$ & $3275(51.9 \%)$ & $<0.001$ & 0.76 (0.69 to 0.82$)$ & 0.72 (0.66 to 0.79$)$ \\
\hline MSM & 692 & $573(16.5 \%)$ & $119(1.9 \%)$ & $<0.001$ & 0.1 (0.08 to 0.12$)$ & 0.07 (0.05 to 0.08$)$ \\
\hline BME & 1094 & $155(4.5 \%)$ & $939(14.9 \%)$ & $<0.001$ & 3.74 (3.14 to 4.46$)$ & 4.65 (3.84 to 5.64$)$ \\
\hline \multicolumn{7}{|l|}{ IMD quintiles† } \\
\hline Most deprived quintile 1 & 1083 & $428(12.3 \%)$ & $655(10.4 \%)$ & 0.002 & $0.78(0.67$ to 0.91$)$ & 0.81 (0.7 to 1.0$)$ \\
\hline 2 & 2172 & $747(21.6 \%)$ & $1425(22.6 \%)$ & 0.70 & $0.975(0.85$ to 1.11$)$ & 0.92 (0.8 to 1.06$)$ \\
\hline 3 & 2276 & $795(22.9 \%)$ & $1481(23.5 \%)$ & 0.46 & 0.95 (0.84 to 1.08$)$ & 0.95 (8.26 to 1.07$)$ \\
\hline 4 & 2400 & $874(25.2 \%)$ & $1526(24.2 \%)$ & 0.08 & $0.89(0.79$ to 1.01$)$ & 0.86 (0.76 to 0.99$)$ \\
\hline Least deprived quintile 5 & 1839 & $622(17.9 \%)$ & $1217(19.3 \%)$ & & - & - \\
\hline Symptomatic & 684 & $322(9.3 \%)$ & $362(5.7 \%)$ & $<0.001$ & 0.59 (0.51 to 0.7$)$ & 0.54 (0.46 to 0.63$)$ \\
\hline UPSI in last 3 days $\ddagger$ & 2702 & $994(28.6 \%)$ & $1708(27.1 \%)$ & 0.1 & 0.92 (0.84 to 1.01$)$ & - \\
\hline Never used a clinic before & 3455 & $1221(35.2 \%)$ & $2234(35.4 \%)$ & 0.83 & $1.01(0.93$ to 1.10$)$ & - \\
\hline
\end{tabular}

*Adjusted ORs (lower and upper $\mathrm{Cls}$ ), adjusted for all other variables significantly associated $(p \leq 0.05)$ in univariate analysis.

tIndex of multi-deprivation quintiles for England.

¥Unprotected sexual incident in last 3 days.

$\mathrm{BME}$, black and ethnic minority; MSM, men who have sex with men. 
choose more rather than fewer tests when given the choice, even though this involved adding more invasive blood tests.

There was a small number $(<5)$ of new diagnoses of syphilis and HIV in groups that had chosen to add these tests to their package and in those who had been recommended the tests according to the 'choose to test' algorithm. We do not know whether any HIV or syphilis diagnoses were missed among those who were not offered testing for these infections and chose not to add them to their testing package. Essex has an HIV diagnosed prevalence rate of 1.27 per 1000 population aged 15-59 and a syphilis diagnostic rate of 4 per 100000 population. ${ }^{9}$ The National HIV testing guidelines recommend a universal offer of HIV testing in sexual health clinics but do not specify whether this includes online services targeting low-risk individuals. ${ }^{10}$ Some MSM chose not to test from certain sites, presumably on the basis of their sexual behaviour.

The intervention was cost saving by reducing the total number of HIV and syphilis tests ordered, but numbers were too small to show whether reduced HIV testing might be associated with a reduction in diagnosis rates. Missed HIV diagnoses would have important cost implications for the local health service in terms of the management of the complications of late diagnosis of HIV or of HIV transmission. These costs have not been factored into the analysis.

It is concerning that most users chose not to access the information available and new strategies to encourage engagement and therefore informed decision-making are required.

Our data suggest that choice of test by service users is feasible and that some groups actively engage with it.

This is an observational study of a first iteration of a new service. It has important limitations including lack of information on the HIV and syphilis positivity of those who chose not to test for these infections and limited information about the sexual behaviour and therefore risk of infection among all participants.

\section{Key messages}

- Where testing choices are provided, the majority of users will choose HIV, syphilis, chlamydia and gonorrhoea as recommended in guidelines.

- Providing users with a choice of tests on an online sexual health service does not significantly affect the number of chlamydia or gonorrhoea diagnoses. Further work is required to understand the effect on diagnoses of HIV and syphilis.

- User-led decision-making on test choice results in cost saving by reducing the number of blood test kits for HIV and syphilis taken, but the cost implications of possible missed HIV diagnoses due to reduced testing is unknown.
Further work is needed to understand how and why decisions to test are made, how to encourage the use of the evidence provided to inform choice of tests, and to further investigate the impact of choice of test on the diagnosis of HIV and syphilis in at-risk populations.

\section{Handling editor Claudia S Estcourt}

Acknowledgements The authors would like to thank Michael Brady for comments on an earlier version of this manuscript.

Contributors PB conceived the study and drafted the manuscript. PB, JS, GH, $\mathrm{CH}$ and $\mathrm{KS}$ contributed to the study design, data interpretation and writing of the manuscript. JS undertook data management and data analysis.

Funding The work of JS and PB on this study was funded from a grant from Guy's and St Thomas' Charity for the evaluation of SH:24 which is part of a grant funding the development of the SH:24 online service.

Competing interests $\mathrm{PB}, \mathrm{GH}$ and $\mathrm{CH}$ are directors of $\mathrm{SH}: 24$, a community-interest company providing web-based sexual health services.

Patient consent for publication Not required.

Ethics approval Ethical approval was obtained from the NRES Committee North of Scotland-Grampian (Ref 15/NS/0031).

Provenance and peer review Not commissioned; externally peer reviewed.

Open access This is an open access article distributed in accordance with the Creative Commons Attribution Non Commercial (CC BY-NC 4.0) license, which permits others to distribute, remix, adapt, build upon this work non-commercially, and license their derivative works on different terms, provided the original work is properly cited, appropriate credit is given, any changes made indicated, and the use is non-commercial. See: http://creativecommons.org/licenses/by-nc/4.0/.

\section{REFERENCES}

1 Coulter A. Person centred care: what works? 2014. Available: http://blogs.bmj.com/ bmj/2014/06/16/angela-coulter-person-centred-care-what-works/

2 Department of Health and Social Care. NHS constitution for England, 2012. Available: https://assets.publishing.service.gov.uk/government/uploads/system/uploads/ attachment_data/file/480482/NHS_Constitution_WEB.pdf

3 Department of Health and Social Care. Health and Social Care Act 2012, 2012. Available: http://www.legislation.gov.uk/ukpga/2012/7/contents/enacted [Accessed 6 Jun 2017].

4 Coulter A. What can e-health do for patients? 2016. Available: https://www. nuffieldtrust.org.uk/news-item/what-can-e-health-do-for-patients

5 Wilson E, Free C, Morris TP, et al. Effect of an Internet-based sexually transmitted infection testing and results service on diagnoses and testing uptake: a single-blind, randomised controlled trial. Lancet 2017;390.

6 BASHH. BASHH CEG guidance on tests for sexually transmitted infections. British Association for Sexual Health and HIV, 2015. Available: https://www.bashhguidelines. org/media/1084/sti-testing-tables-2015-dec-update-4.pdf

7 Turner KME, Zienkiewicz AK, Syred J, et al. Web-based activity within a sexual health economy: observational study. J Med Internet Res 2018;20:e74.

8 Armstrong D, Actors AD. Actors, patients and agency: a recent history. Sociol Health IIIn 2014;36:163-74.

9 Public Health England. Sexual and reproductive health profiles. Available: https:// fingertips.phe.org.uk/profile/sexualhealth/data\#page/0/gid/8000057/pat/6/par/ E12000006/ati/102/are/E10000012 [Accessed 28 Apr 2018].

10 British HIV Association \& British Association of Sexual Health and HIV British Infection Society. UK national guidelines for HIV testing, 2008. Available: http://www.bhiva. org/documents/guidelines/testing/glineshivtest08.pdf 